\title{
Application of ultrasound guidance in the oral and maxillofacial nerve block
}

\author{
Zhiwei Cao ${ }^{1}$, Kun Zhang ${ }^{1}$, Liru Hu ${ }^{1}$, Jian Pan ${ }^{\text {Corresp. } 1}$ \\ ${ }^{1}$ Department of oral surgery, State Key Laboratory of Oral Diseases \& National Clinical Research Center for Oral Diseases \& West China Hospital of \\ Stomatology, Sichuan University, Chengdu, Sichuan, China \\ Corresponding Author: Jian Pan \\ Email address: jianpancn@scu.edu.cn
}

Introduction Nerve block technology is widely used in clinical practice for pain management. Conventional nerve localization methods, which only rely on palpation to identify anatomical landmarks, require experienced surgeons and can be risky.

Visualization technologies like ultrasound guidance can help prevent complications by helping surgeons locate anatomical structures in the surgical area and by guiding the operation using different kinds of images. There are several important and complex anatomical structures in the oral and maxillofacial regions. The current article reviews the application of ultrasound guidance in oral and maxillofacial nerve blocks. Methods We searched the literature on the use of ultrasound guidance for the main nerve block techniques in the oral and maxillofacial regions using both PubMed and MEDLINE and summarized the findings. Results and Discussion A review of the literature showed that ultrasound guidance improves the safety and effectiveness of several kinds of puncture procedures, including nerve blocks. There are two approaches to blocking the mandibular nerve: intraoral and extraoral. This review found that the role of ultrasound guidance is more important in the extraoral approach. There are also two approaches to the blocking of the maxillary nerve and the trigeminal ganglion under ultrasound guidance: the superazygomatic approach and the infrazygomatic approach. The infrazygomatic approach can be further divided into the anterior approach and the posterior approach. It is generally believed that the anterior approach is safer and more effective. This review found that the effectiveness and safety of most oral and maxillofacial nerve block operations can be improved through the use of ultrasound guidance. 
1 Application of ultrasound guidance in the oral and maxillofacial nerve block

3

4

5

6

7 Sichuan, China.

8

9 Address correspondence to:

10 Jian Pan, D.D.S, M.D, Dept. of Oral Surgery, West China Hospital of Stomatology, Sichuan

11 University, No.14, Section 3rd, Renmin Nan Road. 610041. Chengdu, Sichuan, China (email: 12 jianpancn@163.com)

13

14

15

16

17

18

19

20

21

22

23

24

Zhiwei Cao ${ }^{1}$, Kun Zhang ${ }^{1}$, Liru Hu${ }^{1}$, Jian Pan ${ }^{1}$

Affiliations:

1 State Key Laboratory of Oral Diseases \& National Clinical Research Center for Oral Diseases

\& West China Hospital of Stomatology, Sichuan University, Dept. of Oral Surgery, Chengdu, Sichuan, China.

3

4

5

16

18 
ABSTRACT

Introduction Nerve block technology is widely used in clinical practice for pain management. Conventional nerve localization methods, which only rely on palpation to identify anatomical landmarks, require experienced surgeons and can be risky. Visualization technologies like ultrasound guidance can help prevent complications by helping surgeons locate anatomical structures in the surgical area and by guiding the operation using different kinds of images. There are several important and complex anatomical structures in the oral and maxillofacial regions. The current article reviews the application of ultrasound guidance in oral and maxillofacial nerve blocks. Methods This study searched the literature on the use of ultrasound guidance for the main nerve block techniques in the oral and maxillofacial regions using both PubMed and MEDLINE and summarized the findings. Results and Discussion A review of the literature showed that ultrasound guidance improves the safety and effectiveness of several kinds of puncture procedures, including nerve blocks. There are two approaches to blocking the mandibular nerve: intraoral and extraoral. This review found that the role of ultrasound guidance is more important in the extraoral approach. There are also two approaches to the blocking of the maxillary nerve and the trigeminal ganglion under ultrasound guidance: the supra-zygomatic approach and the infra-zygomatic approach. The infra-zygomatic approach can be further divided into the anterior approach and the posterior approach. It is generally believed that the anterior approach is safer and more effective. This review found that the effectiveness and safety of most oral and maxillofacial nerve block operations can be improved through the use of ultrasound guidance.

\section{KEYWORDS}


nerve block; ultrasound; mandibular nerve; maxillary nerve

\section{INTRODUCTION}

The precise goal of a nerve block can be described as "put the right dose of the right drug in the right place" (Denny \& Harrop-Griffiths 2005). Conventional nerve localization methods are based on the identification of anatomical landmarks via palpation on the surface of the body. This technique relies heavily on the experience of the surgeons, and such localization methods are not suitable for patients with anatomical variations in nerves and blood vessels or patients with no perceived anatomical landmarks on the surface of the body. With the development of visualization technologies like ultrasound, CT, and MRI, surgeons can now observe the distribution and direction of nerves and blood vessels. Visualization technologies can greatly reduce the risk of adverse reactions and improve the efficiency of puncture procedures.

Ultrasound guidance is widely used in nerve block procedures for upper and lower limbs and spine and celiac nerves. Ultrasound also has a wide range of applications in the oral and maxillofacial region, including ultrasonic scaling, ultrasound diagnosis, ultrasound-guided puncture procedures, and ultrasound thermo-chemotherapy (Figure 1), but there are relatively few studies on ultrasoundguided oral and maxillofacial nerve blocks. However, nerve block procedures in oral and maxillofacial region also have certain risks. For example, it is reported that routine inferior alveolar nerve block will cause damage to the tongue nerve and the inferior alveolar nerve, the incidence is between 1:26,762 and 1:160,571 (Pogrel \& Thamby 2000), and intravascular needle entrance with aspiration positive can be found in $15.3 \%$ of inferior alveolar nerve block which can lead to 
67 vascular damage and hemorrhage and sometimes intravascular injection(Blanton \& Jeske 2003;

68 Taghavi Zenouz et al. 2008). In addition, oral and maxillofacial nerve block can also cause facial

69 nerve palsy, transient amaurosis, temporary blindness, sudden unilateral deafness, total body

70 hemiparesis, due to incorrect puncture and local anesthetic injection (Crean \& Powis 1999). The

71 current article presents a review of the progress in the application of ultrasound guidance in oral

72 and maxillofacial nerve blocks. This article aims to increase physician awareness of visualization

73 techniques when performing nerve blocks in the maxillofacial region in order to reduce injuries

74 and improve the efficiency of nerve blocks.

75 This article is intended for oral and maxillofacial surgeons, dental emergency doctors, and

76 neurosurgeons, providing them with more visualization technology choices when performing

77 nerve blocks or neuralgia treatment in daily clinical practice. It is our hope that these providers can

78 develop more safe and effective treatment approaches with the help of visualization technology.

\section{METHODS}

811 Literature Search Strategy

82 The present study was conducted following the Preferred Reporting Items for Systematic Reviews

83 and Meta-Analyses (PRISMA) statement (Moher et al. 2009). This study comprehensively

84 searched the PubMed and MEDLINE databases, using the following keywords or Medical Subject

85 Heading $(\mathrm{MeSH})$ terms. "OR" and "AND" operations are used to search the literature on the

86 different nerves and guidance methods. For instance, when searching publications on ultrasound

87 guidance used in inferior nerve blocks, the search terms used were "ultrasound guidance" OR 
88

89

90

91

92

93

94

"US" or "ultrasound-guided" OR "US-guided" AND “inferior alveolar nerve" OR "IANB." Since studies involved both the inferior alveolar and the mandibular nerve, "mandibular nerve" was searched at the same time. Since any review similar to the current one is found, this study did not impose restrictions on the year of publication.

\section{Study Selection Criteria}

The studies were independently reviewed by two authors and any discrepancies were resolved by discussion and consensus. Studies were included based on the following criteria: (1) written in the English language; (2) had human subjects (including autopsy studies); and (3) were a clinical trial, cohort study, narrative study, or case report. Studies that were excluded were: (1) not written in English; (2) did not have human subjects; and (3) did not use visualization technology but used other neural localization technology to guide nerve block procedures. In total, 34 relevant publications were included in review including 3 existing review articles (Figure 2).

\section{Assessment of levels of evidence}

The evidence levels of the articles were assessed by the first author using the 2014 version of the Joanna Briggs Institute (JBI) Levels of Evidence. Evidence was ranked into one of five levels: level $1=$ very high, level $2=$ high, level $3=$ moderate, level $4=$ low and level $5=$ very low.

\section{RESULTS}

34 included studies are grouped according to the target nerves targeted in the study. It was found 
109

110

111

112

113

114

115

116

117

118

119

120

121

122

123

124

125

126

127

128

129

that the most common target nerves for nerve block procedures in the oral and maxillofacial region

are the inferior alveolar nerve, the mandibular nerve, the maxillary nerve and the trigeminal ganglion, and a nerve block of the mandibular nerve and the inferior alveolar nerve are frequently done at the same time, so these two groups in this article were merged. For blocks of the same nerve, different approaches are grouped. In addition to the target nerves mentioned above, there were also studies describing ultrasound-guided nerve blocks of other nerves including the infraorbital nerve and the supraorbital nerve. These were included in the "other nerves" section in this article.

The main anatomical structures and nerves involved in the current article are shown in the lateral view of the skull in Figure 3.

\section{The Mandibular Nerve and The Inferior Alveolar Nerve}

Intraoral injection is the most commonly used method for inferior alveolar nerve blocks (IANB) in clinical practice. The puncture location is identified using several surface landmarks like the pterygomandibular ligament and the buccal fat pad. When practicing this approach, the needle is placed $1 \mathrm{~cm}$ above and parallel to the mandibular occlusal plane. Surgeons administer anesthesia to the inner surface of the mandibular ramus, and then the inferior alveolar nerve can be successfully blocked through the diffusion of anesthetic drugs (Aggarwal et al. 2010). This method is widely used clinically, but studies have shown that its success rate is affected by the specific occasion, which means different types of dental treatment have different requirements for IANB (Abdallah et al. 2016). Studies have proposed different measures to improve the success rate, such 
130

131

132

133

134

135

136

137

138

139

140

141

142

143

144

145

146

147

148

149

150

as supplementary infiltration anesthesia, changing the anesthetic drug dose (Milani et al. 2018), or

using ultrasound-guidance methods. Ultrasound-guided IANB can be divided into intraoral and extraoral approaches.

\subsection{Intraoral approach}

In the intraoral approach, both the ultrasound probe and the injection needle are placed in the mouth. Hannan et al. compared ultrasound-guided IANB to conventional techniques. When comparing the degree of anesthesia of the dental pulp in one side of the mandible, it was found that although the needle tip can be accurately placed around the nerve using ultrasound guidance, no significant difference was found in the success rate between the two techniques. The author also pointed out that the indicator of a successful block used in the study was "pulpal anesthesia," which is different from the commonly used "lip and tongue numbness." Also, in the same study, the inferior alveolar nerve could not be located using ultrasound, so the position of the inferior alveolar artery was used to locate the nerve (Hannan et al. 1999). Chanpong et al. were able to identify the inferior alveolar nerve using a new type of hockey stick-shaped ultrasound probe placed at the patient's pterygomandibular ligament. The average scanning time required to locate the left inferior alveolar nerve was only 19.6 seconds and the scanning time required to locate the right inferior alveolar nerve was 30.5 seconds. The subjects stated that the probe did not cause any significant discomfort. In addition, the author successfully performed IANB on cadavers using this method by injecting a dye in order to simulate the diffusion of anesthesia drugs around the nerve when performing this procedure (Chanpong et al. 2013). 
In summary, there are several criteria to evaluate the success of traditional IANB, and accurately placing the needle around the nerve is not the only factor that affects anesthesia. Future studies addressing the safety of this method are needed as there are only a few studies (including basic research and clinical research) on the intraoral approach to ultrasound-guided inferior alveolar nerve blocks. It is too early to conclude that the introduction of ultrasound has any effect on the success rate of IANB in the intraoral approach. More studies are needed to explore whether ultrasound can guide this operation.

\subsection{Extraoral approach}

In the extraoral approach of ultrasound-guided inferior alveolar nerve (or mandibular nerve) blocks, the ultrasound probe and the puncture point are located outside of the mouth. The most common purpose behind the extraoral approach is to inject the anesthetic drugs into the pterygomandibular space. The relative positions of the ultrasound probe and the needle tip, and the correct recognition of the anatomical structures from the ultrasound images are important for this procedure. Kumita et al. reported a type of extraoral approach to performing an ultrasoundguided maxillary and inferior alveolar nerve block to induce analgesia after orthognathic surgery. In this method, the ultrasound probe was placed caudad to the zygomatic arch to observe the maxillary artery in the pterygomandibular space. The selected injection site was just around the maxillary artery to help the anesthetic drug infiltrate the inferior alveolar nerve. This study also used the position of the maxillary artery to locate the nerve in the ultrasound images (Kumita et 
172 IANB in patients having drug-related osteonecrosis and undergoing mandibular resection under

173 general anesthesia. The after-surgery analgesic effect was better in the experimental group

174 compared to the control group of patients who did not receive IANB, and the total amount of

175 opioids used in the experimental group was significantly less than the amount used by patients in

176 the control group (Kojima et al. 2020). The above studies showed that ultrasound-guided injection

177 of local anesthetics into the pterygomandibular space can achieve satisfactory results in inferior

178 alveolar nerve (and mandibular nerve) blocks. As an alternative to injecting the anesthetic drugs

179 into the pterygomandibular space, Kampitak et al. performed a new ultrasound-guided selective

180 mandibular nerve block in cadavers, called the lateral pterygoid plate approach, where the drugs

181 were injected into the base of the skull. During the surgery, the cadaver's mouth was wide open,

182 the posterior and superior edges of the lateral pterygoid plate were identified using ultrasound, and

183 the adjacent mandibular nerve and its branches were successfully stained by injecting a dye,

184 indicating that a successful nerve block can be performed in the same way (Kampitak et al. 2018b).

185 Tsuchiya et al. also used a similar approach, in which the lateral pterygoid plate was used as a

landmark. In ten cases of parotidectomy, low-molecular weight dextran and local anesthetics were

used to block the mandibular nerve under ultrasound guidance, successfully reducing the

involuntary movement of the muscles due to surgical stimulation during operation, thus reducing

the need for general anesthesia (Tsuchiya et al. 2019).

In summary, there are relatively more studies on the extraoral approach of ultrasound-guided 
193

194

196

approach. In some variations of the extraoral approach of the mandibular nerve or IANB, patients do not need to open their mouths. Since there are some patients who require a mandibular nerve or IANB that cannot open their mouths due to trauma or pain, the extraoral approach of the alveolar nerve (or mandibular nerve) block is sometimes necessary. However, in the extraoral approach, because the needle goes deeper and the adjacent structures are more complex, the ultrasound can better guide the needle. Jain et al. performed closed-mouth high-position mandibular nerve blocks known as the Vazirani-Akinosi method (Prabhu Nakkeeran et al. 2019) and extraoral ultrasoundguided mandibular nerve blocks in patients with pain and trismus due to fracture or acute pain, before administering general anesthesia. To check for differences between these two block methods, the visual analogue scale (VAS) pain scores and the degree of relief from trismus before and after the block for each patient was compared. The results suggest that ultrasound can help accurately locate nerves and blood vessels anterior to the condyle and assist with injecting anesthetics into the correct location. The ultrasound-guided group of patients required fewer anesthetic drugs, had fewer adverse reactions, and showed better anesthetic effects and higher success rates of block (Jain et al. 2016). The comparison of the different extraoral approaches of IANB is shown in Table 1 and Figure 4.

\section{Maxillary Nerve}

The extraoral approach is the most common approach used in ultrasound-guided maxillary nerve blocks. In this procedure, the ultrasound probe is usually placed below the zygomatic arch. The extraoral approach can be further divided into the infra-zygomatic and supra-zygomatic 
214 approaches depending on the location of the puncture point (Anugerah et al. 2020).

215

216

2.1 Supra-zygomatic approach.

217 Sola et al. and Chiono et al. performed bilateral maxillary nerve blocks using ultrasound guidance

218 and the supra-zygomatic approach for pain management in infants who underwent cleft palate

219 repair surgery. In ultrasound images, anatomical structures in the pterygopalatine fossa and needle

220 tip positions could be clearly distinguished in real-time images. The anesthetic drug was injected

221 into the pterygopalatine fossa using ultrasound guidance, and the surgeons could control the spread

222 of the anesthetic over time. The arterial pulsation could also be monitored to help avoid the risk of

223 vascular puncture. Although the maxillary nerve could not be directly identified using ultrasound

224 images, the success rate and safety of the maxillary nerve block in this study were both improved.

225 After the surgery, all patients with a maxillary nerve block had better pain management and used

226 fewer analgesic drugs (Chiono et al. 2014; Sola et al. 2012). Another study performed maxillary

227 nerve blocks during maxillary osteotomy operations in adult patients using supra-zygomatic

228 approach and determined that this method was safer as it avoids the risk of penetrating the orbital

229 contents through the infraorbital fissure (Bouzinac et al. 2014). Echaniz et al. used this method to

230 conduct a study on cadavers to identify the anesthetic drug dose required for a maxillary nerve

231 block. The results showed that only $1 \mathrm{~mL}$ of liquid was needed to cover the nerve surface (Echaniz

232 et al. 2019). In the study by Kumita et al., a maxillary nerve block was performed right after a

233 mandibular nerve block, and the pterygoid fossa could be observed by adjusting the position of the

234 probe. In this study, the insertion point was located at the angle formed by the superior edge of the

Peer] reviewing PDF | (2021:06:62977:2:0:NEW 2 Nov 2021) 
235

236

zygomatic arch and the posterior orbital rim, and the injection site was at the lateral pterygoid plate. The authors pointed out that using ultrasound-guided maxillary and inferior alveolar nerve blocks at the same time significantly improved the effectiveness of perioperative analgesia during gnathoplasty (Kumita et al. 2017).

\subsection{Infra-zygomatic Approach}

The supra-zygomatic approach mention above is considered a safer approach by many scholars, but normally it can only be performed using out-of-plane techniques, which are difficult. Moreover, due to the occlusion of the zygomatic arch, there is a period when the needle is seemingly invisible in the ultrasound and the surgeons have to rely on their experience (Anugerah et al. 2020). So, there are infra-zygomatic approach which can solve these problems.

Kampitak et al. introduced a kind of ultrasound-guided maxillary nerve block using the infrazygomatic approach in cadavers, using ultrasound images of the posterior edge of the maxilla and the lateral pterygoid plate as landmarks. In this study, while the mouth of the cadaver was wide open, the injection needle could approach the pterygopalatine fossa through the front edge of the lateral pterygoid plate. This method successfully simulated the block of the maxillary nerve, pterygopalatine ganglion, greater and lesser palatine nerves, and middle and posterior superior alveolar nerves by injecting a dye in place of an analgesic to see how the analgesic would spread in the nerves (Kampitak et al. 2018a). The authors claimed that after administering general anesthesia, the degree of opening of the mouth could be increased. (Kampitak \& Shibata 2019) In the infra-zygomatic approach, there are two ways for the needle to enter: the anterior and posterior 
approaches. Alfaro-de la Torre et al. compared these two approaches and found that the anterior

257

258

259

260

261

262

263

264

265

266

267

268

269

270

271

272

273

274

275

276 approach, in which the needle goes front-to-back, can effectively avoid damage to important structures like the facial nerve, parotid gland, and maxillary artery (Alfaro-de la Torre et al. 2019).

However, the anterior approach is more difficult to perform. In addition to the two approaches described above, Takahashi et al. reported a novel infra-zygomatic approach, in which the needle passes from in front of the coronoid process. In this paper, this review refer to this method as "the coronoid approach." The main advantages of this novel method are that the path of the needle is far away from the main blood vessels, and the needle would not advance to the pterygopalatine fossa but instead to the infratemporal crest, which is safer. The mandibular nerve can also be blocked at the same time by tilting the ultrasound probe slightly posteriorly and advancing the needle vertically. Patient discomfort could also be reduced since this method can be performed while the patient's mouth is closed(Takahashi \& Suzuki 2017; Takahashi \& Suzuki 2018). Chang et al. and Ying et al. introduced another version of the infra-zygomatic approach where the needle goes between the coracoid process and the maxilla and easily passes through the fissura pterygomaxillaris to reach the pterygopalatine fossa, effectively avoiding the bone structures(Chang et al. 2017; Ying \& Du 2017).

There are several studies on ultrasound-guided maxillary nerve blocks, but there is still no consensus on which method is better. The comparison of the different approaches to ultrasoundguided maxillary nerve blocking is shown in Table 2 and Figure 5. 
277

278

279

280

281

282

283

284

285

286

287

288

289

290

291

292

293

294

295

296

297

\section{Trigeminal Ganglion}

An ultrasound-guided trigeminal ganglion puncture is similar to a maxillary nerve puncture. A nerve block of the trigeminal ganglion is used as a treatment for neuralgia of the trigeminal nerve and its branches (Allam et al. 2018). Nader et al. injected anesthetic drugs and steroids under ultrasound guidance into the pterygopalatine fossa of fifteen patients who had trigeminal neuralgia and who had failed both surgery and drug treatments. The results showed that $80 \%$ of patients achieved complete analgesia in three branches of the nerve. The authors hypothesize that the high success of this procedure is because the pterygopalatine fossa communicates with the foramen rotundum and the supraorbital fissure (Nader et al. 2013a). The injection in the pterygopalatine fossa helps diffuse the anesthetic drugs to the middle cranial fossa through the foramen rotundum, thereby blocking the three branches of the trigeminal nerve (Nader et al. 2013a; Nader et al. 2013b). Although the trigeminal ganglion is situated relatively deeper, by adjusting the angle of the ultrasound probe and the injection needle, surgeons can still advance the needle through the upper head of the lateral pterygoid muscle and the pterygomaxillary fissure, and finally to the foramen rotundum through the pterygopalatine fossa (Chuang \& Chen 2015). A subsequent study used this ultrasound-guided puncture method on a patient with trigeminal neuralgia. The authors performed pulsed radiofrequency via the pterygopalatine fossa, achieving satisfactory analgesic effects, and no recurrence was observed (Nader et al. 2015). Kumar et al. used the same procedure on patients undergoing maxillofacial surgery for pain management, reducing the amount of opioids these patients used after surgery (Kumar et al. 2018).

Ultrasound-guided trigeminal nerve block technology generally uses the infra-zygomatic 
298 approach. Zou et al. proposed a supra-zygomatic approach, where both the ultrasound probe and

299 the puncture point are both located above the zygomatic arch. After identifying the landmark

300 structures like the maxilla, the great wing of the sphenoid bone, and the pterygopalatine fossa using

301 ultrasound imagery, the anesthetic drugs were injected onto the surface of the maxilla. The comparison of the skin sensation of the patients as well as MRI images both before and after the operation showed that this method helped spread the anesthetic drugs to the target nerves, and both the mandibular and maxillary nerves were blocked successfully. However, the blocking effect of the ophthalmic nerve was poor. This method is also more comfortable for patients as it does not require the mouth to be open. In-plane technology can also help reduce the difficulty of puncturing

(Zou et al. 2020). The best way to perform an ultrasound-guided trigeminal nerve block, however, is still unclear. A comparison of the different approaches to ultrasound-guided maxillary nerve blocks is shown in Table 3 and Figure 6.

\section{Other Nerves}

312 Apart from the larger branches of the trigeminal nerve like the maxillary and the mandibular

313 nerves, some small branches in the oral and maxillofacial region can also be blocked using 314 ultrasound guidance (Allam et al. 2018). However, due to their superficial position, these nerves 315 can be blocked easily using conventional landmark palpation, so the application of ultrasound has not been widely promoted in this area.

318 Michalek et al. used ultrasound to observe the position of the infraorbital foramen on a skull model. 
319 The authors concluded that it is feasible to block the infraorbital nerve under ultrasound guidance,

320 and when the puncture point is located intraorally, the block can be performed using the in-plane

321 technique because the path of the needle is longer (Michalek et al. 2013). Other studies used an

322 ultrasound-guided infraorbital nerve block for patients with trigeminal neuralgia and isolated

323 infraorbital neuralgia, and showed that rapid and satisfactory analgesia was achieved after surgery;

324 although, neuralgia recurred in both studies (Takechi et al. 2015). The results from another

325 randomized double-blind clinical trial of ultrasound-guided infraorbital nerve blocks suggest that

326 dexmedetomidine combined with bupivacaine have a superior analgesic effect than

327 dexamethasone combined with bupivacaine after cleft palate repair surgery (El-Emam \& El Motlb

328 2019).

329

330 Cadaver studies (Spinner \& Kirschner 2012) have demonstrated that ultrasound can also be used

331 to guide injection into the supraorbital, infraorbital, and mental nerves. Luo et al. and Ren et al.

332 studied the treatment of refractory supraorbital neuralgia with radiofrequency pulses and

333 radiofrequency thermocoagulation, respectively, using ultrasound guidance. The results showed

334 that both methods achieved satisfactory analgesic effects and no obvious adverse reactions were

335 observed. (Luo et al. 2018; Ren et al. 2020)

336

337 Hafeez et al. performed greater palatine nerve blocks with ultrasound guidance with a hockey

338 stick-shaped ultrasound probe in patients and cadavers. They found that although ultrasound could

339 locate the greater palatine artery and identify the greater palatine foramen and its direction 
340 effectively in the normal and edentulous maxilla, the block procedure could be challenging. The

341 authors reported that with a more suitable size of ultrasound probe and a more suitable dose of

342 local anesthetics, ultrasound may be used in pre-procedural localization to achieve a successful

343 greater palatine nerve block (Hafeez et al. 2014).

344

345 In the maxillofacial region, although some nerves are superficial, they are accompanied by blood

346 vessels, and the adjacent structures are complex. Ultrasound may play an important role in

347 visualization and guidance of puncture operations. Ultrasound technology has the potential to

348 significantly improve nerve blocks and the treatment of neuralgia.

\section{CONCLUSION}

351

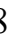

(1)

The biggest advantage of ultrasound is its convenience and real-time imaging capabilities. These real-time images may help surgeons observe the blood vessels and nerves around an injection area and the diffusion of anesthetics in real-time, thereby improving the success rate and safety of puncture procedures. While there are relatively few studies on the application of ultrasound guidance in oral and maxillofacial nerve blocks and no widely recognized standards, this comprehensive literature review suggests the superiority of using ultrasound to guide nerve blocks in the oral and maxillofacial region.

Also, ultrasound technology is constantly developing and there have been several suggestions to enhance positioning abilities (such as needle visualization technology, endoscopic ultrasound, etc.) 
361 (O'Donnell \& Loughnane 2019). More research on ultrasound guidance is needed in the future.

362 With the advancement of imaging technologies, more problems may be solved with support from

363

364

365

366

367

368

369

370

371

372

373

374

375

376

377

378

379

380

381

382

383

384

385

386

387

388

389

390

391

392

clinical trials and medical practitioners.

4

6

67

8

\section{REFERENCES}

Abdallah FW, Macfarlane AJ, and Brull R. 2016. The Requisites of Needle-to-Nerve Proximity for Ultrasound-Guided Regional Anesthesia: A Scoping Review of the Evidence. Reg Anesth Pain Med 41:221-228. 10.1097/aap.0000000000000201

Aggarwal V, Singla M, and Kabi D. 2010. Comparative evaluation of anesthetic efficacy of Gow-Gates mandibular conduction anesthesia, Vazirani-Akinosi technique, buccal-plus-lingual infiltrations, and conventional inferior alveolar nerve anesthesia in patients with irreversible pulpitis. Oral Surg Oral Med Oral Pathol Oral Radiol Endod 109:303-308. 10.1016/j.tripleo.2009.09.016

Alfaro-de la Torre P, Boada Pie S, Fajardo Perez M, and Gonzalez-Arnay E. 2019. Ultrasound-guided maxillary nerve block via the pterygopalatine fossa: anterior versus posterior infrazygomatic approach. Reg Anesth Pain Med. 10.1136/rapm-2018-100077

Allam AE, Khalil AAF, Eltawab BA, Wu WT, and Chang KV. 2018. Ultrasound-Guided Intervention for Treatment of Trigeminal Neuralgia: An Updated Review of Anatomy and Techniques. Pain Res Manag 2018:5480728. 10.1155/2018/5480728

Anugerah A, Nguyen K, and Nader A. 2020. Technical considerations for approaches to the ultrasound-guided maxillary nerve block via the pterygopalatine fossa: a literature review. Reg Anesth Pain Med 45:301-305. 10.1136/rapm-2019-100569

Blanton PL, and Jeske AH. 2003. Avoiding complications in local anesthesia induction: anatomical considerations. $J$ Am Dent Assoc 134:888-893. 10.14219/jada.archive.2003.0288

Bouzinac A, Tournier JJ, Dao M, and Delbos A. 2014. Ultrasound-guided maxillary nerve block in adults: feasibility and efficiency for postoperative analgesia after maxillary osteotomy. Minerva Anestesiol 80:860-861.

Chang KV, Lin CS, Lin CP, Wu WT, and 脰 z 莽 akar L. 2017. Recognition of the Lateral Pterygoid Muscle and Plate during Ultrasound-Guided Trigeminal Nerve Block. $J$ Clin Diagn Res 11:Ul01-ul02. $10.7860 / \mathrm{jcdr} / 2017 / 27724.9932$

Peer] reviewing PDF | (2021:06:62977:2:0:NEW 2 Nov 2021) 
393

394

395

396

397

398

399

400

401

402

403

404

405

406

407

408

409

410

411

412

413

414

415

416

417

418

419

420

421

422

423

424

425

426

427

428

429

430

431

432

433

Chanpong B, Tang R, Sawka A, Krebs C, and Vaghadia H. 2013. Real-time ultrasonographic visualization for guided inferior alveolar nerve injection. Oral Surg Oral Med Oral Pathol Oral Radiol 115:272-276. 10.1016/j.oooo.2012.10.019

Chiono J, Raux O, Bringuier S, Sola C, Bigorre M, Capdevila X, and Dadure C. 2014. Bilateral suprazygomatic maxillary nerve block for cleft palate repair in children: a prospective, randomized, double-blind study versus placebo. Anesthesiology 120:1362-1369. 10.1097/aln.0000000000000171

Chuang YW, and Chen CH. 2015. Landmark of Ultrasound-Guided Trigeminal Block: Lateral Pterygoid Muscle. Pain Physician 18:E933-934.

Crean SJ, and Powis A. 1999. Neurological complications of local anaesthetics in dentistry. Dent Update 26:344-349. 10.12968/denu.1999.26.8.344

Denny NM, and Harrop-Griffiths W. 2005. Location, location, location! Ultrasound imaging in regional anaesthesia. Br J Anaesth 94:1-3. 10.1093/bja/aei001

Echaniz G, Chan V, Maynes JT, Jozaghi Y, and Agur A. 2019. Ultrasound-guided maxillary nerve block: an anatomical study using the suprazygomatic approach. Can J Anaesth. 10.1007/s12630-019-01481-x

El-Emam EM, and El Motlb EAA. 2019. Comparative Evaluation of Dexamethasone and Dexmedetomidine as Adjuvants for Bupivacaine in Ultrasound-Guided Infraorbital Nerve Block for Cleft Lip Repair: A Prospective, Randomized, Double-Blind Study. Anesth Essays Res 13:354-358. 10.4103/aer.AER_14_19

Hafeez NS, Sondekoppam RV, Ganapathy S, Armstrong JE, Shimizu M, Johnson M, Merrifield P, and Galil KA. 2014. Ultrasound-guided greater palatine nerve block: a case series of anatomical descriptions and clinical evaluations. Anesth Analg 119:726-730. 10.1213/ane.0000000000000329

Hannan L, Reader A, Nist R, Beck M, and Meyers WJ. 1999. The use of ultrasound for guiding needle placement for inferior alveolar nerve blocks. Oral Surg Oral Med Oral Pathol Oral Radiol Endod 87:658-665. 10.1016/s1079-2104(99)70156-3

Jain G, Yadav G, Singh AP, Singh Y, and Singh DK. 2016. Efficacy of ultrasound-guided mandibular block in predicting safer anesthetic induction. Anesth Essays Res 10:184-188. 10.4103/0259-1162.176406

Kampitak W, and Shibata Y. 2019. Reply to Dr Alfaro-de la Torre et al. Reg Anesth Pain Med. 10.1136/rapm-2018100239

Kampitak W, Tansatit T, and Shibata Y. 2018a. A Cadaveric Study of Ultrasound-Guided Maxillary Nerve Block Via the Pterygopalatine Fossa: A Novel Technique Using the Lateral Pterygoid Plate Approach. Reg Anesth Pain Med 43:625-630. 10.1097/aap.0000000000000790

Kampitak W, Tansatit T, and Shibata Y. 2018b. A Novel Technique of Ultrasound-Guided Selective Mandibular Nerve Block With a Lateral Pterygoid Plate Approach: A Cadaveric Study. Reg Anesth Pain Med 43:763767. 10.1097/aap.0000000000000760

Kojima Y, Murouchi T, Akiba M, and Oka T. 2020. Ultrasound-guided inferior alveolar nerve block for postoperative analgesia after mandibular sequestrectomy: A single-center retrospective study. $J$ Clin Anesth 60:39-40. 10.1016/j.jclinane.2019.08.026

Kumar A, Sinha C, Kumar A, Kumari P, and Mukul SK. 2018. Ultrasound-guided trigeminal nerve block and its comparison with conventional analgesics in patients undergoing faciomaxillary surgery: Randomised control trial. Indian J Anaesth 62:871-875. 10.4103/ija.IJA_256_18

Kumita S, Murouchi T, and Arakawa J. 2017. Ultrasound-guided maxillary and inferior alveolar nerve blocks for postoperative analgesia in gnathoplasty. Asian J Anesthesiol 55:89-90. 10.1016/j.aja.2017.11.001

Peer] reviewing PDF | (2021:06:62977:2:0:NEW 2 Nov 2021) 
Luo F, Lu J, and Ji N. 2018. Treatment of Refractory Idiopathic Supraorbital Neuralgia Using Percutaneous Pulsed Radiofrequency. Pain Practice 18.

Michalek P, Donaldson W, McAleavey F, Johnston P, and Kiska R. 2013. Ultrasound imaging of the infraorbital foramen and simulation of the ultrasound-guided infraorbital nerve block using a skull model. Surg Radiol Anat 35:319-322. 10.1007/s00276-012-1039-3

Milani AS, Froughreyhani M, Rahimi S, Zand V, and Jafarabadi MA. 2018. Volume of Anesthetic Agents and IANB Success: A Systematic Review. Anesth Prog 65:16-23. 10.2344/anpr-65-01-03

Moher D, Liberati A, Tetzlaff J, and Altman DG. 2009. Preferred reporting items for systematic reviews and metaanalyses: the PRISMA statement. PLoS Med 6:e1000097. 10.1371/journal.pmed.1000097

Nader A, Bendok BR, Prine JJ, and Kendall MC. 2015. Ultrasound-Guided Pulsed Radiofrequency Application via the Pterygopalatine Fossa: A Practical Approach to Treat Refractory Trigeminal Neuralgia. Pain Physician 18:E411-415.

Nader A, Kendall MC, De Oliveria GS, Chen JQ, Vanderby B, Rosenow JM, and Bendok BR. 2013a. Ultrasoundguided trigeminal nerve block via the pterygopalatine fossa: an effective treatment for trigeminal neuralgia and atypical facial pain. Pain Physician 16:E537-545.

Nader A, Schittek H, and Kendall MC. 2013b. Lateral pterygoid muscle and maxillary artery are key anatomical landmarks for ultrasound-guided trigeminal nerve block. Anesthesiology 118:957. 10.1097/ALN.0b013e31826d3dfc

O'Donnell BD, and Loughnane F. 2019. Novel nerve imaging and regional anesthesia, bio-impedance and the future. Best Pract Res Clin Anaesthesiol 33:23-35. 10.1016/j.bpa.2019.02.001

Pogrel MA, and Thamby S. 2000. Permanent nerve involvement resulting from inferior alveolar nerve blocks. $J \mathrm{Am}$ Dent Assoc 131:901-907. 10.14219/jada.archive.2000.0308

Prabhu Nakkeeran K, Ravi P, Doss GT, and Raja KK. 2019. Is the Vazirani-Akinosi Nerve Block a Better Technique Than the Conventional Inferior Alveolar Nerve Block for Beginners? J Oral Maxillofac Surg 77:489-492. 10.1016/j.joms.2018.08.034

Ren H, Shen Y, and Luo F. 2020. Treatment of Supraorbital Neuralgia Using Ultrasound-Guided Radiofrequency Thermocoagulation of the Supraorbital Nerve: A Retrospective Study. J Pain Res 13:251-259. 10.2147/jpr.S228720

Sola C, Raux O, Savath L, Macq C, Capdevila X, and Dadure C. 2012. Ultrasound guidance characteristics and efficiency of suprazygomatic maxillary nerve blocks in infants: a descriptive prospective study. Paediatr Anaesth 22:841-846. 10.1111/j.1460-9592.2012.03861.x

Spinner D, and Kirschner JS. 2012. Accuracy of ultrasound-guided superficial trigeminal nerve blocks using methylene blue in cadavers. Pain Med 13:1469-1473. 10.1111/j.1526-4637.2012.01480.x

Taghavi Zenouz A, Ebrahimi H, Mahdipour M, Pourshahidi S, Amini P, and Vatankhah M. 2008. The Incidence of Intravascular Needle Entrance during Inferior Alveolar Nerve Block Injection. $J$ Dent Res Dent Clin Dent Prospects 2:38-41. 10.5681/joddd.2008.008

Takahashi H, and Suzuki T. 2017. A novel approach for performing ultrasound-guided maxillary nerve block. J Clin Anesth 43:61-62. 10.1016/j.jclinane.2017.09.015

Takahashi H, and Suzuki T. 2018. A modified anterior approach for ultrasound-guided maxillary nerve block and its application to the mandibular nerve block. J Clin Anesth 46:96-98. 10.1016/j.jclinane.2018.01.015

Takechi K, Konishi A, Kikuchi K, Fujioka S, Fujii T, Yorozuya T, Kuzume K, and Nagaro T. 2015. Real-time 
ultrasound-guided infraorbital nerve block to treat trigeminal neuralgia using a high concentration of tetracaine dissolved in bupivacaine. Scand J Pain 6:51-54. 10.1016/j.sjpain.2014.10.003

Tsuchiya M, Mizutani K, Yabe M, Mori T, and Ueda W. 2019. Ultrasound-guided mandibular nerve block with local anesthetic and low-molecular weight dextran helps reduce anesthetic requirements for parotidectomy. Minerva Anestesiol 85:202-203. 10.23736/s0375-9393.18.12966-х

Ying YL, and Du DP. 2017. Introduction of Another Approach of Ultrasound-Guided Maxillary Nerve Block via Pterygopalatine Fossa. Journal of Clinical \& Diagnostic Research 11.

Zou F, Gong W, Zhang D, and Fan K. 2020. A novel approach for performing ultrasound-guided trigeminal nerve block: Above the zygomatic arch. J Clin Anesth 60:36-38. 10.1016/j.jclinane.2019.08.028

\section{Figure captions}

Figure 1: Application of ultrasound in the oral and maxillofacial region. (A) Ultrasound Diagnostic System. (B) Ultrasonic scaler tip. (C) Ultrasound used to scan and diagnose the examination site. (D) Ultrasound guided puncture operation. (E) Ultrasound thermo-chemotherapy. (F) Ultrasonic scaling. (G) Ultrasonic root canal irrigation.

Figure 2: Study selection process.

Figure 3: Anatomy structure of part of the skull in lateral view. (A) Lateral view of part of the skull with mouth closed; (B) Lateral view of part of the skull after the zygomatic arch is removed with mouth closed; the pterygopalatine fossa is covered with coracoid process; (C) Lateral view of part of the skull where the zygomatic arch and mandible are transparent; (D) Lateral view of part of the skull after the zygomatic arch is removed with mouth opened; the pterygopalatine fossa can be seen. (E) Enlarged image of the pterygopalatine fossa.

SB: sphenoid bone; TB: temporal bone; CB: Cheekbone; ZA: zygomatic arch; TG: Trigeminal ganglion; FR: foramen rotundum; FO: foramen ovale; CP: coracoid process, LPP: lateral pterygoid 
501

502

503

504

505

506

507

508

509

510

511

512

513

514

plate; PF: pterygopalatine fossa; MdN: mandibular nerve; MxN: maxillary nerve; LN: lingual nerve; IAN: inferior alveolar nerve; PSAN: posterior superior alveolar nerve; PG: pterygopalatine ganglion.

Figure 4: The needle position of different methods of performing an ultrasound-guided mandibular nerve block in extraoral approach with mouth opened

1: The trajectory of the needle is perpendicular to the sagittal plane to reach the PMS, described by Kumita et al.

2: The needle reaches the posterior edge of the LPP in the infra-zygomatic approach described by Kampitak et al.

Figure 5: (A) The needle position of different methods of performing an ultrasound-guided maxillary nerve block while the mouth is closed or slightly opened. The dotted line indicates that the needle is blocked by the zygomatic arch or coracoid process. 1: the supra-zygomatic approach described by Sola et al; 2: the coracoid approach of the infra-zygomatic approach described by Takahashi et al. (B) The needle position of different methods of performing an ultrasound-guided maxillary nerve block while the mouth is opened. 3: Posterior approach of the infra-zygomatic approach described by Nader et al. where the mouth is slightly opened; 4: Anterior approach of the infra-zygomatic approach described by Kampitak et al. in which the anterior edge of LPP is used as the landmark for puncturing. 
522 Figure 6: The needle position of different methods of performing an ultrasound-guided Trigeminal 523 Ganglion block.

524 Studies describe that an injection into the pterygopalatine fossa can make the anesthetic drugs diffuse through the foramen rotundum to the middle cranial fossa, thereby blocking three branches

of the trigeminal nerve.

527 1: The infra-zygomatic approach described by Nader et al.

528 2: The supra-zygomatic approach described by Zou et al.

529

$530 \quad$ Table captions

531 Table 1: Comparison of Different Approaches of Ultrasound Guided Mandibular Nerve and Inferior Alveolar 532 Nerve Blocks

533 ZA: zygomatic arch; LPP: lateral pterygoid plate; PS: pterygomandibular space

535 Table 2: Comparison of Different Approaches of Ultrasound Guided Maxillary Nerve Blocks

536 ZA: zygomatic arch; LPP: lateral pterygoid plate; PF: pterygopalatine fossa

538 Table 3: Comparison of Different Approaches of Ultrasound Guided Trigeminal Ganglion Blocks

539 ZA: zygomatic arch; LPP: lateral pterygoid plate; PF: pterygopalatine fossa 
Figure 1

Application of ultrasound in the oral and maxillofacial region.

(A) Ultrasound Diagnostic System. (B) Ultrasonic scaler tip. (C) Ultrasound used to scan and diagnose the examination site. (D) Ultrasound guided puncture operation. (E) Ultrasound thermo-chemotherapy. (F) Ultrasonic scaling. (G) Ultrasonic root canal irrigation.

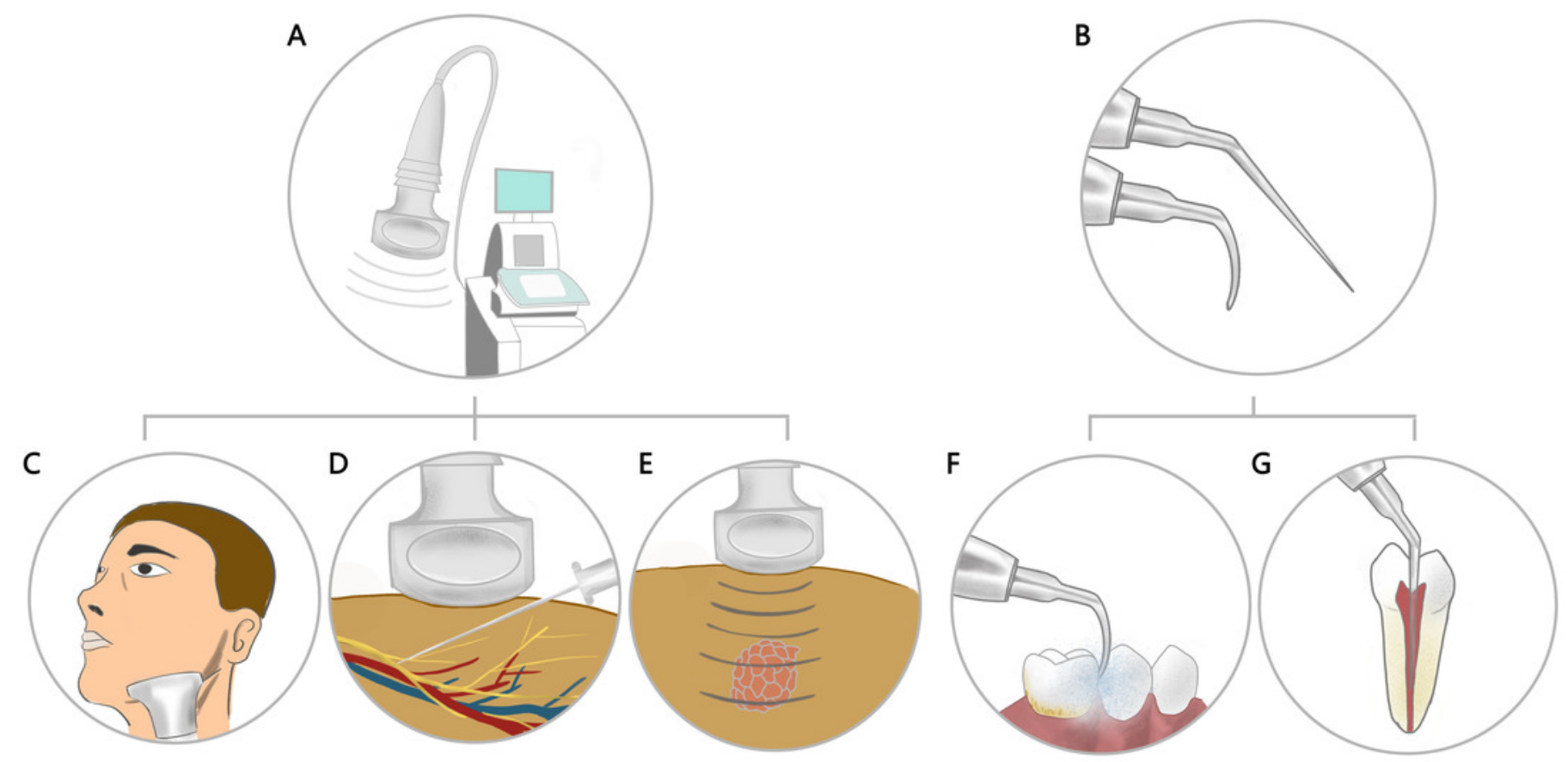


Figure 2

Study selection process.

Study selection process. 


\section{Identification of studies via databases and registers}

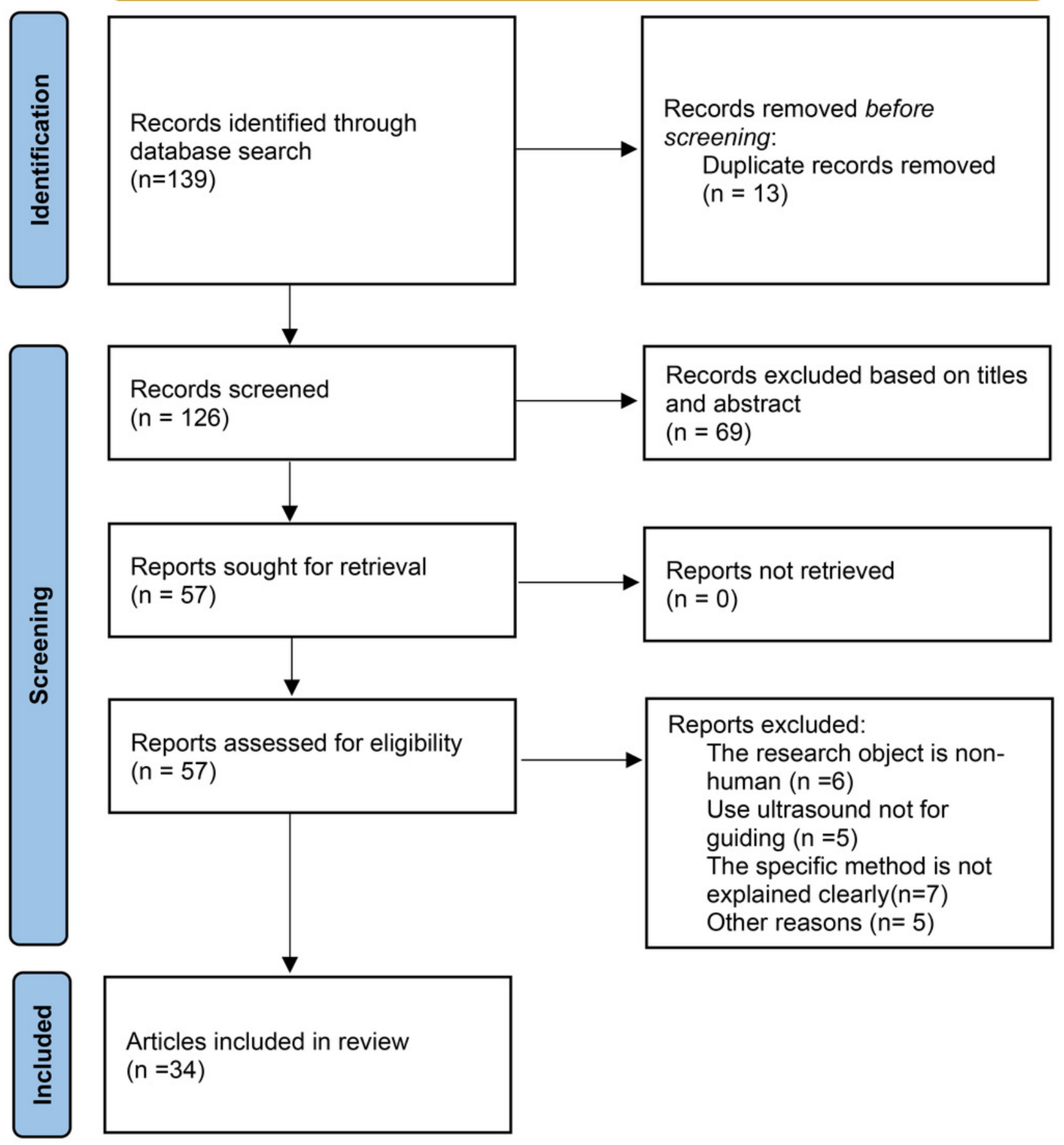




\section{Figure 3}

Anatomy structure of part of the skull in lateral view.

(A) Lateral view of part of the skull with mouth closed; (B) Lateral view of part of the skull after the zygomatic arch is removed with mouth closed; the pterygopalatine fossa is covered with coracoid process; (C) Lateral view of part of the skull where the zygomatic arch and mandible are transparent; (D) Lateral view of part of the skull after the zygomatic arch is removed with mouth opened; the pterygopalatine fossa can be seen. (E) Enlarged image of the pterygopalatine fossa.

SB: sphenoid bone; TB: temporal bone; CB: Cheekbone; ZA: zygomatic arch; TG: Trigeminal ganglion; FR: foramen rotundum; FO: foramen ovale; CP: coracoid process, LPP: lateral pterygoid plate; PF: pterygopalatine fossa; MdN: mandibular nerve; MxN: maxillary nerve; LN: lingual nerve; IAN: inferior alveolar nerve; PSAN: posterior superior alveolar nerve; PG: pterygopalatine ganglion. 

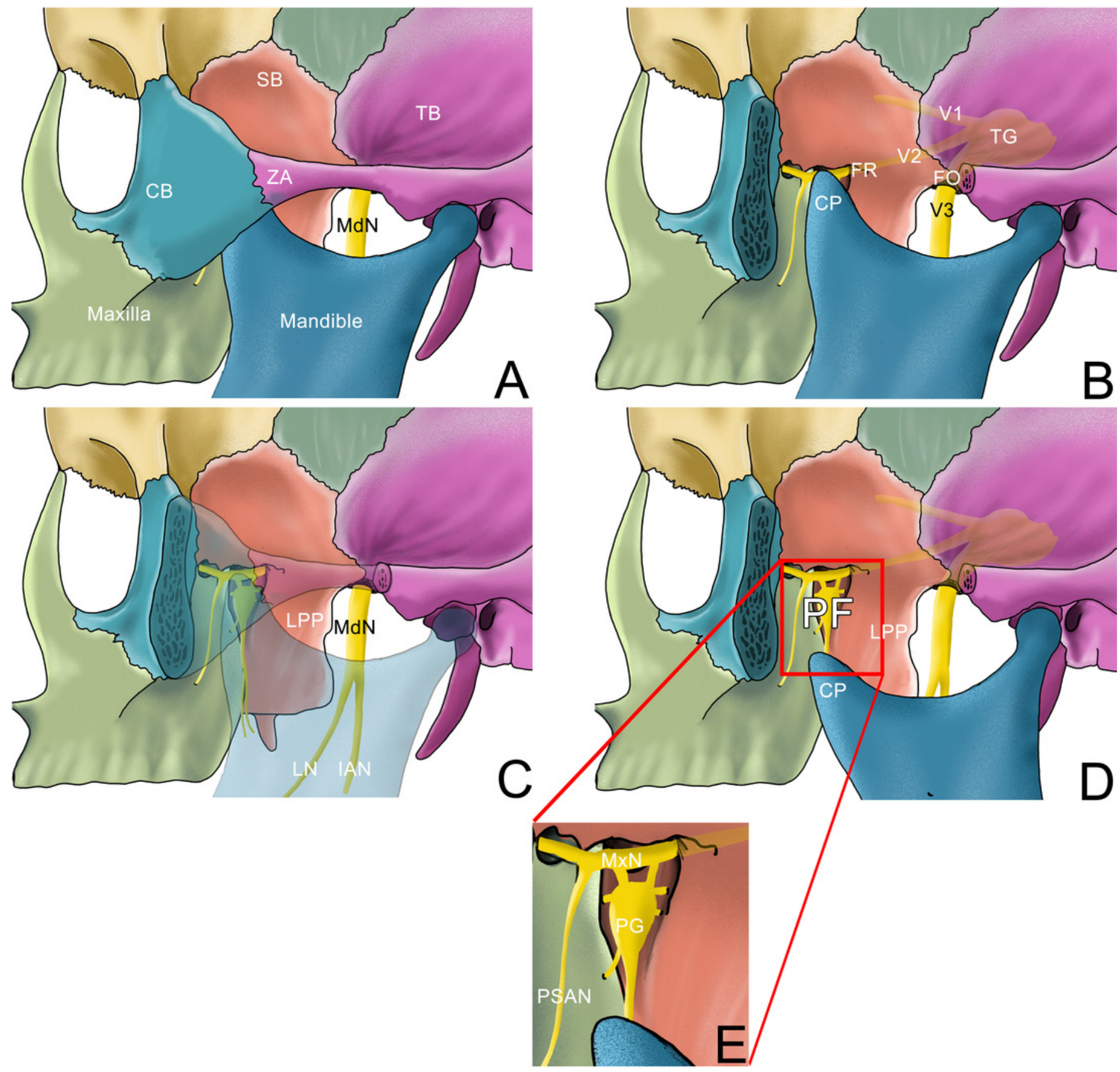


\section{Figure 4}

The needle position of different methods of performing an ultrasound-guided mandibular nerve block in extraoral approach with mouth opened

1: The trajectory of the needle is perpendicular to the sagittal plane to reach the PMS, described by Kumita et al. 2: The needle reaches the posterior edge of the LPP in the infrazygomatic approach described by Kampitak et al.

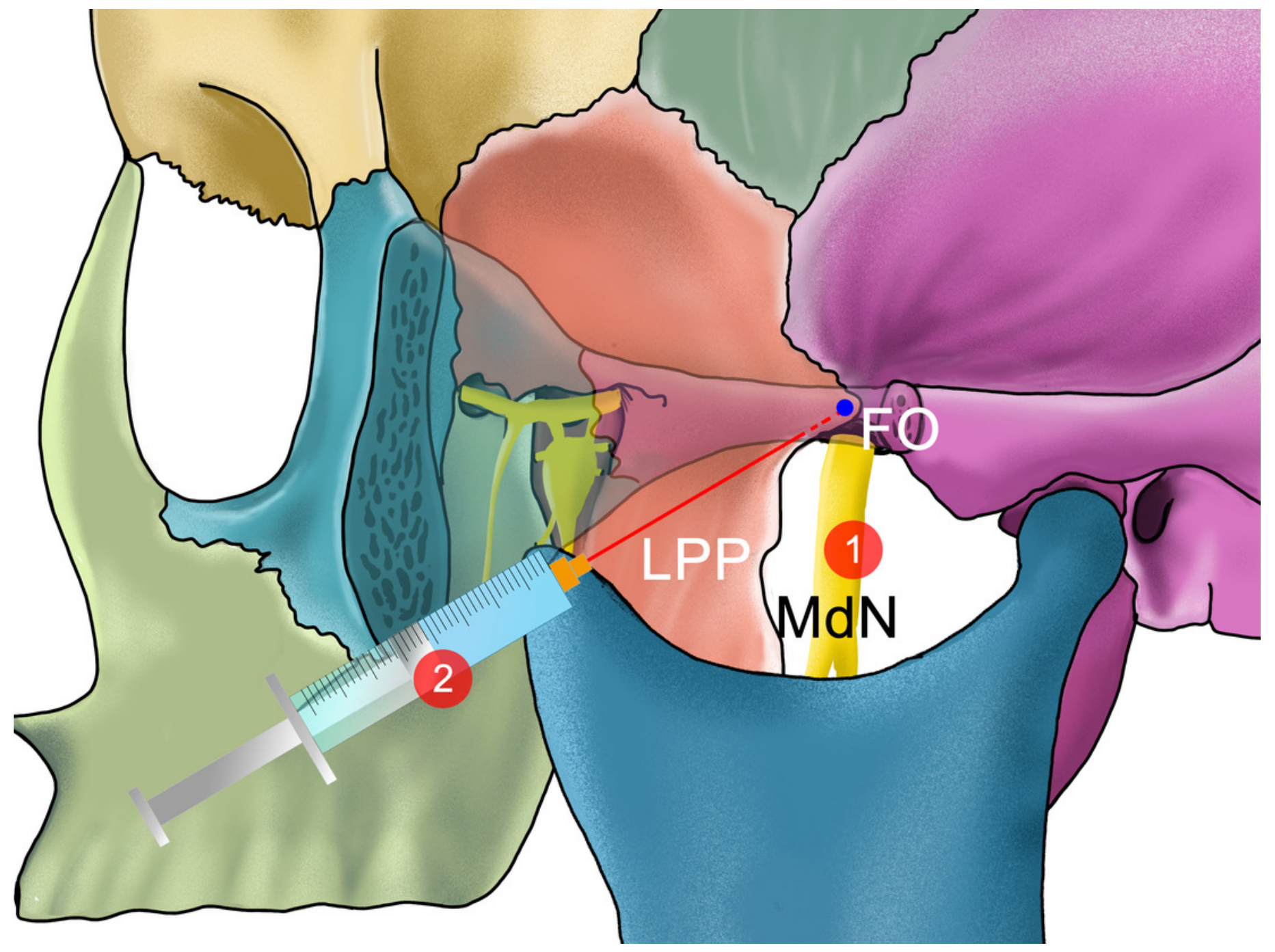




\section{Figure 5}

The needle position of different methods of performing an ultrasound-guided mandibular nerve block

(A) The needle position of different methods of performing an ultrasound-guided maxillary nerve block while the mouth is closed or slightly opened. The dotted line indicates that the needle is blocked by the zygomatic arch or coracoid process. 1: the supra-zygomatic approach described by Sola et al; 2: the coracoid approach of the infra-zygomatic approach described by Takahashi et al. (B) The needle position of different methods of performing an ultrasound-guided maxillary nerve block while the mouth is opened. 3: Posterior approach of the infra-zygomatic approach described by Nader et al. where the mouth is slightly opened; 4: Anterior approach of the infra-zygomatic approach described by Kampitak et al. in which the anterior edge of LPP is used as the landmark for puncturing.
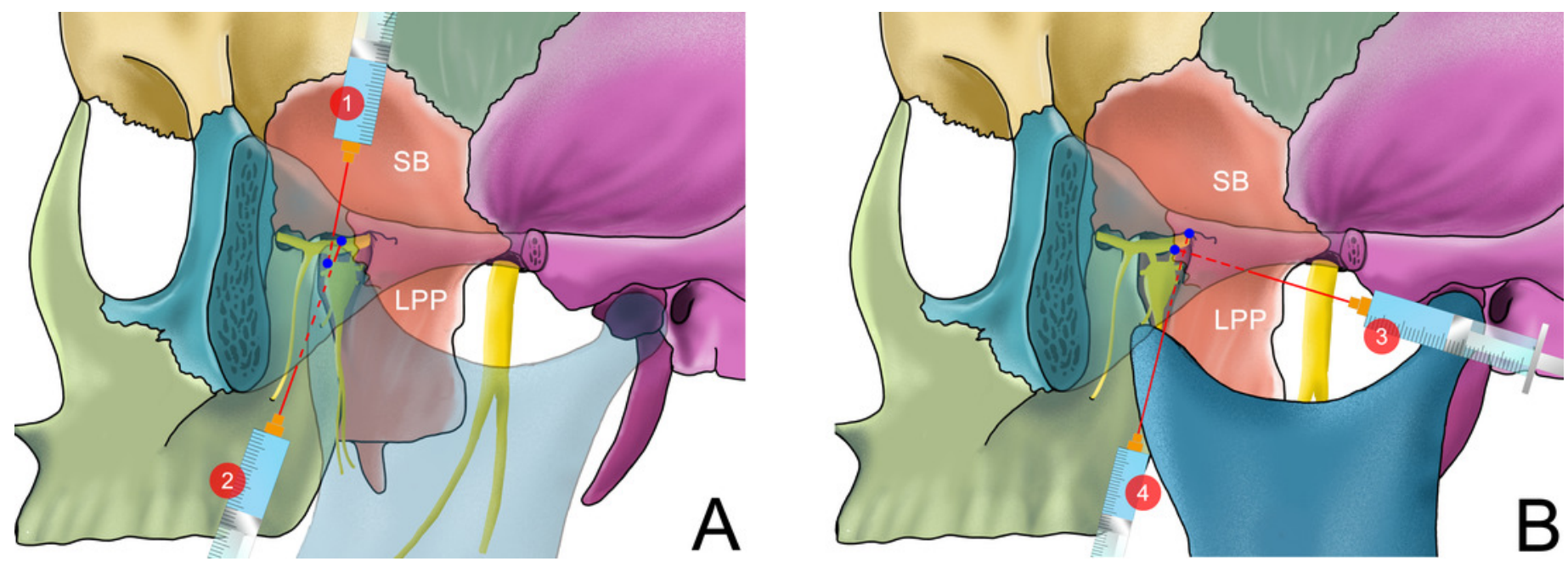


\section{Figure 6}

The needle position of different methods of performing an ultrasound-guided Trigeminal Ganglion block.

Studies describe that an injection into the pterygopalatine fossa can make the anesthetic drugs diffuse through the foramen rotundum to the middle cranial fossa, thereby blocking three branches of the trigeminal nerve. 1: The infrazygomatic approach described by Nader et al. 2: The suprazygomatic approach described by Zou et al.

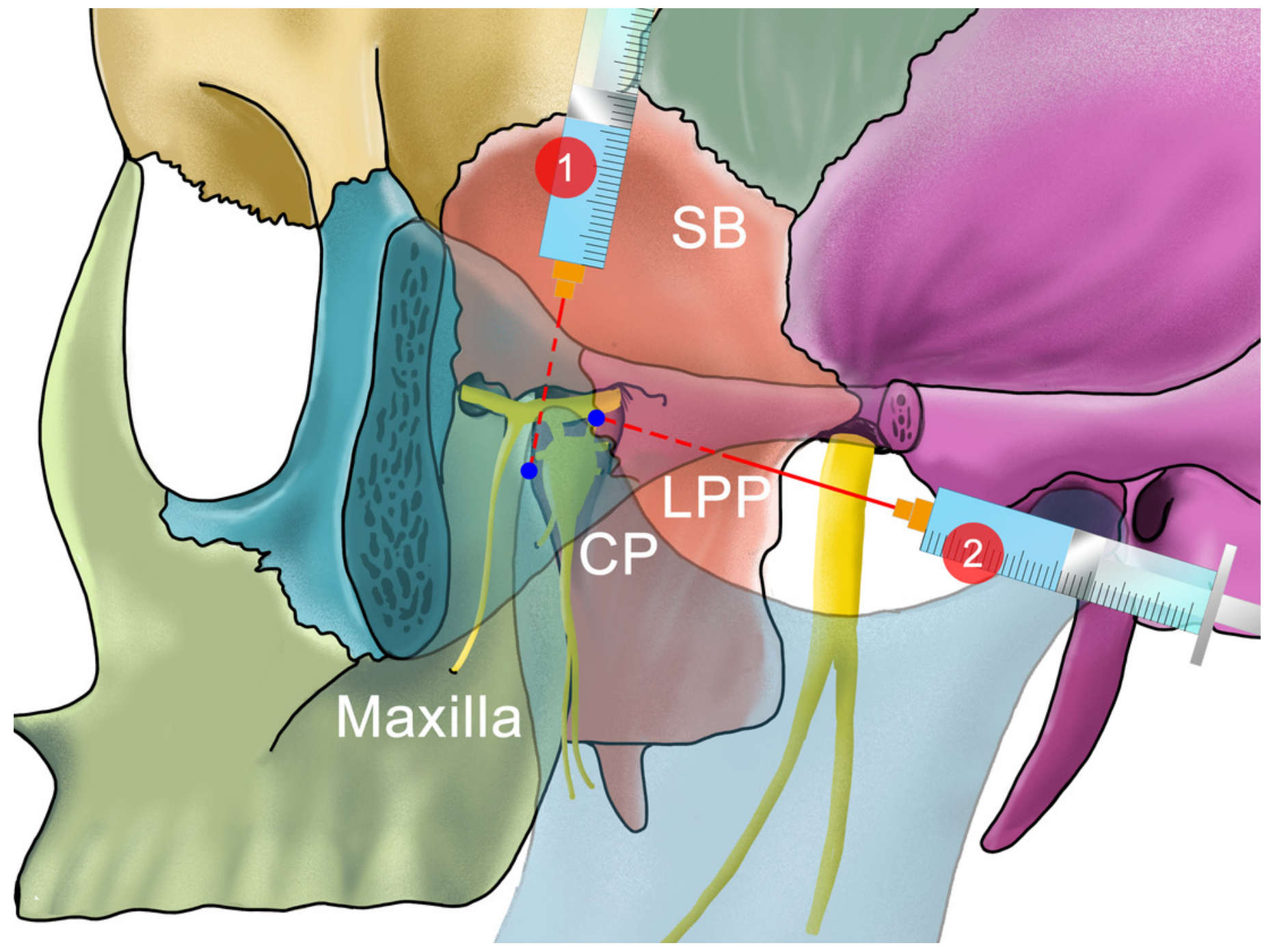




\section{Table $\mathbf{1}$ (on next page)}

Table 1: Comparison of Different Approaches of Ultrasound Guided Mandibular Nerve and Inferior Alveolar Nerve Blocks

ZA: zygomatic arch; LPP: lateral pterygoid plate; PS: pterygomandibular space 


\begin{tabular}{|c|c|c|c|c|c|c|c|c|c|}
\hline $\begin{array}{c}\text { Approac } \\
\mathbf{h}\end{array}$ & Authors & Subjects & $\begin{array}{l}\text { Levels of } \\
\text { Evidence }\end{array}$ & $\begin{array}{c}\text { Position of ultrasound } \\
\text { probe }\end{array}$ & $\begin{array}{l}\text { Information of } \\
\text { the probe }\end{array}$ & $\begin{array}{l}\text { Puncture point } \\
\text { / Inject point }\end{array}$ & $\begin{array}{l}\text { Ultrasound- } \\
\text { guided } \\
\text { puncture } \\
\text { method } \\
\end{array}$ & Main advantages & $\begin{array}{c}\text { Possible } \\
\text { disadvantages }\end{array}$ \\
\hline \multirow[t]{2}{*}{ Intraoral } & $\begin{array}{c}\text { Hannna, } \\
1999\end{array}$ & Patients & 1 & $\begin{array}{l}\text { The oral mucosa on } \\
\text { medial aspect of the } \\
\text { mandibular ramus }\end{array}$ & $\begin{array}{l}\text { Acuson EV519 } \\
\text { frequency unclear }\end{array}$ & $\begin{array}{l}\text { Intraoral/ } \\
\text { IAN at PS }\end{array}$ & In plane & $\begin{array}{l}\text { Locate the nerve } \\
\text { accurately, } \\
\text { Avoid inadvertent }\end{array}$ & $\begin{array}{l}\text { The success } \\
\text { rate was not } \\
\text { significantly }\end{array}$ \\
\hline & $\begin{array}{c}\text { Chanpong } \\
\text {,2013 }\end{array}$ & $\begin{array}{l}\text { Patients } \\
\text { and } \\
\text { cadavers }\end{array}$ & 4 & Pterygomandibular raphe & $\begin{array}{c}\text { HST15-8/20 linear } \\
\text { probe } \\
8 \text { - to } 15-\mathrm{MHz}\end{array}$ & Intraoral/ IAN at PS & - & $\begin{array}{c}\text { intraneural } \\
\text { injection and entry } \\
\text { into surrounding } \\
\text { structures }\end{array}$ & $\begin{array}{l}\text { improved; } \\
\text { Possible } \\
\text { increase in } \\
\text { operating time }\end{array}$ \\
\hline \multirow[t]{4}{*}{ Extraoral } & $\begin{array}{l}\text { Kumita, } \\
2017 ; \\
\text { Kojima } \\
2020\end{array}$ & Patients & 4 & Caudad to ZA. & $\begin{array}{l}\text { linear probe } \\
5-12 \mathrm{MHz}\end{array}$ & $\begin{array}{l}\text { Below the ZA/ } \\
\text { Maxillary artery }\end{array}$ & Out of plane & & $\begin{array}{c}\text { Large degree } \\
\text { of mouth } \\
\text { opening }\end{array}$ \\
\hline & $\begin{array}{l}\text { Kampitak, } \\
2018\end{array}$ & Cadavers & 5 & $\begin{array}{c}\text { Transversely below the } \\
\text { ZA. }\end{array}$ & $\begin{array}{c}\text { SonoSite X-Porte } \\
\text { 8-3 MHz }\end{array}$ & $\begin{array}{c}\text { Below the ZA/ The } \\
\text { Posterior border of } \\
\text { the LPP }\end{array}$ & In plane & & $\begin{array}{c}\text { Large degree } \\
\text { of mouth } \\
\text { opening }\end{array}$ \\
\hline & $\begin{array}{c}\text { Tsuchiya, } \\
2019\end{array}$ & Patients & 4 & $\begin{array}{l}\text { Below and parallel to the } \\
\text { ZA }\end{array}$ & $\begin{array}{l}\text { curvilinear probe } \\
4.5 \mathrm{MHz}\end{array}$ & $\begin{array}{c}\text { - /Dorsal edge of } \\
\text { LPP }\end{array}$ & - & & \\
\hline & Jain, 2016 & Patients & 1 & $\begin{array}{l}\text { Superior to the mandible } \\
\text { (linear ultrasound probe); } \\
\text { below the zygoma and } \\
\text { anterior to the mandibular } \\
\text { condyle (cardiac probe) }\end{array}$ & $\begin{array}{c}12 \mathrm{~L}-\mathrm{RS} \text { linear } \\
\text { probe } \\
8-13 \mathrm{MHz} \\
\text { Or } \\
\text { cardiac probe } \\
2.8-4 \mathrm{MHz}\end{array}$ & $\begin{array}{l}\text { Superior (linear } \\
\text { ultrasound probe) or } \\
\text { posterior (cardiac } \\
\text { probe) to the probe/ } \\
\text { Mandibular nerve }\end{array}$ & $\begin{array}{l}\text { Out of plane } \\
\text { (linear } \\
\text { ultrasound } \\
\text { probe) } \\
\text { In-line (cardiac } \\
\text { probe) }\end{array}$ & $\begin{array}{c}\text { No need to open } \\
\text { mouth } \\
\text { Reduce the dosage } \\
\text { of local anesthetics } \\
\text { and avoid vascular } \\
\text { puncture }\end{array}$ & \\
\hline
\end{tabular}


ZA: zygomatic arch; LPP: lateral pterygoid plate; PS: pterygomandibular space 


\section{Table 2 (on next page)}

Comparison of Different Approaches of Ultrasound Guided Maxillary Nerve Blocks

ZA: zygomatic arch; LPP: lateral pterygoid plate; PF: pterygopalatine fossa 


\begin{tabular}{|c|c|c|c|c|c|c|c|c|c|}
\hline proach & Authors & Subjects & $\begin{array}{l}\text { Levels of } \\
\text { evidence }\end{array}$ & $\begin{array}{c}\text { Position of } \\
\text { ultrasound probe }\end{array}$ & $\begin{array}{c}\text { Puncture point and needle } \\
\text { position/ } \\
\text { Inject point }\end{array}$ & $\begin{array}{l}\text { Informa- } \\
\text { tion of the } \\
\text { probe }\end{array}$ & $\begin{array}{l}\text { Ultrasound } \\
\text {-guided } \\
\text { puncture } \\
\text { method }\end{array}$ & Main advantages & Possible disadvantag \\
\hline $\begin{array}{l}\text { Supra- } \\
\text { gomatic } \\
\text { pproach }\end{array}$ & $\begin{array}{c}\text { Sola, } 2012 \\
\text { Chiono, } \\
2014 \\
\text { Bouzinac, } \\
2014 \\
\text { Echaniz, } \\
2019\end{array}$ & Cadavers & 3 & $\begin{array}{l}\text { Infra-zygomatic } \\
\text { area, over the } \\
\text { maxilla, with an } \\
\text { inclination of } 45^{\circ} \text { in } \\
\text { both the frontal and } \\
\text { horizontal planes }\end{array}$ & $\begin{array}{l}\text { The angle formed by the } \\
\text { superior edge of the ZA and } \\
\text { the posterior edge of orbital } \\
\text { rim. / The greater wing of } \\
\text { the sphenoid at PF }\end{array}$ & $\begin{array}{l}\text { linear } \\
\text { array } \\
\text { probe. } \\
8-13 \mathrm{MHz}\end{array}$ & Out of plane & $\begin{array}{l}\text { Reduce postoperative } \\
\text { analgesic dose } \\
\text { Help locate the needle } \\
\text { and prevent the puncture } \\
\text { of orbital contents }\end{array}$ & - \\
\hline $\begin{array}{l}\text { Interior } \\
\text { oproach } \\
\text { (infra- } \\
\text { gomatic) }\end{array}$ & $\begin{array}{l}\text { Kampitak, } \\
2018\end{array}$ & Cadavers & 5 & $\begin{array}{l}\text { Transversely below } \\
\text { the ZA and was } \\
\text { tilted from the } \\
\text { caudal to the cranial } \\
\text { direction }\end{array}$ & -/ At the top of LPP at PF & $\begin{array}{l}\text { curved } \\
\text { array } \\
\text { probe } \\
3-8 \mathrm{MHz}\end{array}$ & In plane & $\begin{array}{l}\text { By inserting the needle } \\
\text { from front to back, } \\
\text { avoiding puncture the } \\
\text { parotid gland, the facial } \\
\text { nerve and maxillary } \\
\text { artery. }\end{array}$ & $\begin{array}{l}\text { Large degree of mout } \\
\text { opening; } \\
\text { A very sharp needle en } \\
\text { angle is needed; } \\
\text { Sonographic visualizat } \\
\text { can be difficult }\end{array}$ \\
\hline $\begin{array}{l}\text { osterior } \\
\text { oproach } \\
\text { (infra- } \\
\text { gomatic) }\end{array}$ & $\begin{array}{l}\text { Alfaro-de, } \\
2019\end{array}$ & Cadavers & 5 & - & $-/-$ & Not clear & - & Easier to perform & $\begin{array}{l}\text { It can possibly lead } t \\
\text { injury to some vital } \\
\text { organs, and needle } \\
\text { pathway is longer }\end{array}$ \\
\hline $\begin{array}{l}\text { oracoid } \\
\text { oproach } \\
\text { (infra- } \\
\text { gomatic) }\end{array}$ & $\begin{array}{l}\text { Takahashi, } \\
2017,2018\end{array}$ & Patients & 4 & $\begin{array}{l}\text { Below the } \\
\text { zygomatic process } \\
\text { of the maxilla and } \\
\text { tilted slightly in the } \\
\text { superior direction. }\end{array}$ & $\begin{array}{c}\text { Between the maxilla and } \\
\text { coronoid process/ } \\
\text { Infratemporal crest }\end{array}$ & Not clear & Out of plane & $\begin{array}{l}\text { The needle does not enter } \\
\text { into PF; } \\
\text { Patients don't have to } \\
\text { open their mouth; } \\
\text { Mandibular nerve can be } \\
\text { blocked at the same time }\end{array}$ & - \\
\hline
\end{tabular}

Table 2: Comparison of Different Approaches of Ultrasound Guided Maxillary Nerve Block 
ZA: zygomatic arch; LPP: lateral pterygoid plate; PF: pterygopalatine fossa 


\section{Table 3 (on next page)}

Comparison of Different Approaches of Ultrasound Guided Trigeminal Ganglion Blocks

ZA: zygomatic arch; LPP: lateral pterygoid plate; PF: pterygopalatine fossa 


\begin{tabular}{|c|c|c|c|c|c|c|c|c|c|}
\hline Approach & Authors & Subjects & $\begin{array}{c}\text { Levels } \\
\text { of } \\
\text { evidence }\end{array}$ & $\begin{array}{c}\text { Position of ultrasound } \\
\text { probe }\end{array}$ & $\begin{array}{c}\text { Puncture point } \\
\text { and needle } \\
\text { position/ Inject } \\
\text { point } \\
\end{array}$ & $\begin{array}{l}\text { Informa- } \\
\text { tion of the } \\
\text { probe }\end{array}$ & $\begin{array}{l}\text { Ultrasound- } \\
\text { guided } \\
\text { puncture } \\
\text { method }\end{array}$ & $\begin{array}{c}\text { Main } \\
\text { advantages }\end{array}$ & $\begin{array}{c}\text { Possible } \\
\text { disadvantages }\end{array}$ \\
\hline $\begin{array}{l}\text { Infra-zygomatic } \\
\text { approach }\end{array}$ & $\begin{array}{c}\text { Nader } \\
2013 \text {, } \\
2015 \text {; } \\
\text { Chuang } \\
2015 \\
\text { Kumar, } \\
2018\end{array}$ & Patients & 4 & $\begin{array}{l}\text { Below the ZA, } \\
\text { longitudinally on the } \\
\text { side of face. } \\
\text { Below the ZA, } \\
\text { longitudinally on the } \\
\text { side of face and superior } \\
\text { to mandibular notch, } \\
\text { anterior to the } \\
\text { mandibular condyle }\end{array}$ & $\begin{array}{l}\text { Parallel to the } \\
\text { probe / Below } \\
\text { the lateral } \\
\text { pterygoid } \\
\text { muscle, anterior } \\
\text { to the LPP at PF }\end{array}$ & $\begin{array}{c}\text { 11-L } \\
\text { transducer } \\
\text { probe. } \\
\text { Frequency } \\
\text { not clear } \\
\text { M-Turbo } \\
\text { linear array } \\
\text { probe. } \\
\text { 7-12 } \mathrm{MHz}(\end{array}$ & $\begin{array}{c}\text { In plane } \\
\text { Out of plane }\end{array}$ & $\begin{array}{l}\text { The subject's } \\
\text { mouth was just } \\
\text { slightly opened }\end{array}$ & $\begin{array}{l}\text { Mouth was kept } \\
\text { open }\end{array}$ \\
\hline $\begin{array}{l}\text { Supra-zygomatic } \\
\text { approach }\end{array}$ & $\begin{array}{l}\text { Zou, } \\
2020\end{array}$ & Patients & 4 & $\begin{array}{l}\text { Longitudinally on the } \\
\text { side of the face just on } \\
\text { the ZA and shifted } \\
\text { cranially temporal fossa } \\
\text { appeared and the ZA } \\
\text { vanished in the } \\
\text { ultrasound images. }\end{array}$ & $\begin{array}{l}\text { Posterior side of } \\
\text { the probe/ } \\
\text { Maxilla surface }\end{array}$ & $\begin{array}{c}\text { convex array } \\
\text { probe } \\
\text { 2- to } 5-\mathrm{MHz}\end{array}$ & In plane & $\begin{array}{l}\text { The needle } \\
\text { does not enter } \\
\text { into PF; } \\
\text { Patients don't } \\
\text { have to open } \\
\text { their mouth. }\end{array}$ & $\begin{array}{c}\text { Ophthalmic } \\
\text { nerve cannot be } \\
\text { blocked }\end{array}$ \\
\hline
\end{tabular}

